\title{
IgG4-related disease presenting as recurrent scleritis combined with optic neuropathy
}

\author{
Su Jin Kim ${ }^{1,2}$, Seung Uk Lee ${ }^{3}$, Min Seung Kang ${ }^{1,2}$, Jung Hyo Ahn ${ }^{1,2}$, Jonghoon Shin ${ }^{1,2}$, Choul Yong Park ${ }^{4,5}$ and \\ Ji Eun Lee L $^{1,2^{*}}$ (D)
}

\begin{abstract}
Background: We report a case of atypical presentation of IgG4-related disease (IgG4-RD) with recurrent scleritis and optic nerve involvement.

Case presentation: A 61-year-old male presented with ocular pain and injection in his left eye for 2 months. Ocular examination together with ancillary testing led to the diagnosis of scleritis, which relapsed in spite of several courses of steroid treatment. After cessation of steroid, the patient complained of severe retro-orbital pain and blurred vision. His best corrected vision was count finger, the pupil was mid-dilated and a relative afferent pupillary defect was found. Funduscopic examination demonstrated disc swelling. Magnetic resonance imaging (MRI) showed enhancing soft tissue encasing the left globe, medial rectus muscle and optic nerve. Systemic work-up revealed multiple nodules in right lower lung and a biopsy showed histopathological characteristics of lgG4-RD. Long-term treatment with corticosteroids and a steroid-sparing agent (methotrexate) led to significant improvement in signs and symptoms with no recurrence for 2 years.

Conclusions: This case highlights the significance of lgG4-RD in the differential diagnosis of recurrent scleritis. IgG4$\mathrm{RD}$ may cause optic neuropathy resulting in visual loss. Early diagnosis and proper treatment can prevent irreversible organ damage and devastating visual morbidity.
\end{abstract}

Keywords: Extraocular muscle, IgG4-related disease, Optic neuropathy, Recurrent scleritis

\section{Background}

IgG4-related disease (IgG4-RD) is a newly identified clinical entity characterized by an IgG4-positive multiorgan lymphoplasmacytic infiltrate, associated with fibrosis or sclerosis [1-3]. Since IgG4-RD was first described in conjunction with autoimmune sclerosing pancreatitis, the disorder has been expanded to

\footnotetext{
*Correspondence: jiel75@hanmail.net

'Department of Ophthalmology, Pusan National University Yangsan Hospital, Pusan National University School of Medicine, 20 Geumo-ro, Mulgeum-eup, Yangsan-si, Gyeongsangnam-do 50612, South Korea

${ }^{2}$ Research Institute for Convergence of Biomedical Science and Technology, Pusan National University Yangsan Hospital, Yangsan, South Korea Full list of author information is available at the end of the article
}

incorporate several previously distinct inflammatory conditions [4-6].

Ophthalmic involvement predominantly affects the lacrimal gland and typically presents as idiopathic orbital inflammation and chronic sclerosing dacryoadenitis [7, 8]. Here, we report an atypical case of IgG4-RD revealed by chronic relapsing scleritis with optic nerve sheath and extra-ocular muscle (EOM) involvement and confirmed by pathological analysis from the pulmonary nodules.

\section{Case presentation}

A 61-year-old man presented with unilateral ocular pain and injection for 2 months. His best corrected visual

(c) The Author(s). 2021 Open Access This article is licensed under a Creative Commons Attribution 4.0 International License, which permits use, sharing, adaptation, distribution and reproduction in any medium or format, as long as you give appropriate credit to the original author(s) and the source, provide a link to the Creative Commons licence, and indicate if changes were made. The images or other third party material in this article are included in the article's Creative Commons licence, unless indicated otherwise in a credit line to the material. If material is not included in the article's Creative Commons licence and your intended use is not permitted by statutory regulation or exceeds the permitted use, you will need to obtain permission directly from the copyright holder. To view a copy of this licence, visit http://creativecommons.org/licenses/by/4.0/ The Creative Commons Public Domain Dedication waiver (http://creativecommons.org/publicdomain/zero/1.0/) applies to the data made available in this article, unless otherwise stated in a credit line to the data. 


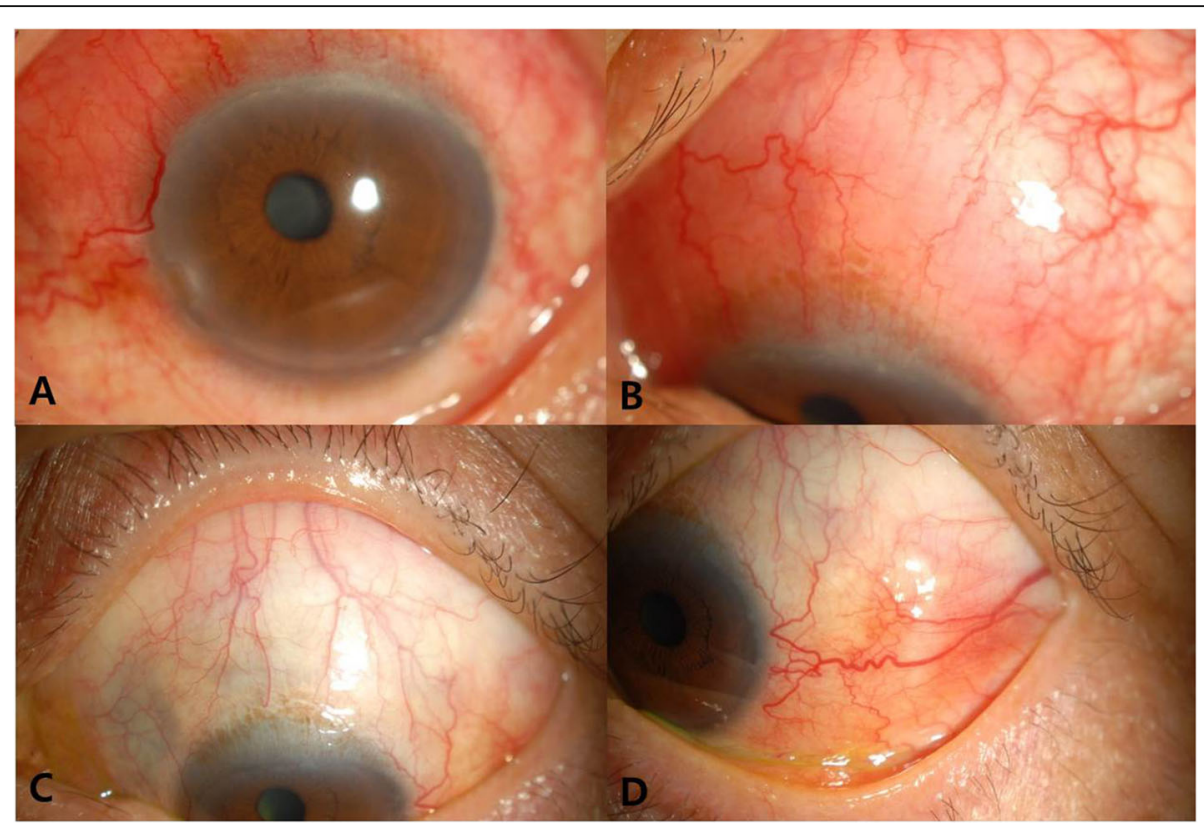

Fig. 1 Clinical picture of the patient demonstrating scleritis. Slit lamp examination showed a localized inflamed superonasal bulbar conjunctival swelling in the left eye $(\mathbf{a} \& \mathbf{b})$. During steroid treatment, superonasal lesion had been resolved (c) but new lesion was developed on the temporal area (d)

acuity was 20/20 bilaterally and intraocular pressures were normal. Slit lamp examination showed a localized inflamed superonasal bulbar conjunctival swelling in the form of scleritis in his left eye (Fig. 1a and b). Normal fundus with no choroidal folds or serous retinal detachment was found. On peripheral blood tests, full blood count, leucocyte count, erythrocyte sedimentation rate and C-reactive protein were normal. Testing for antinuclear antibodies, antineutrophil cytoplasmic antibodies, rheumatoid factor, anti-dsDNA IgG, angiotensin converting enzyme and HLA-B27 were normal or negative. The patient was diagnosed with anterior scleritis and treated with topical steroid (fluometholone 4 times a day) and oral prednisolone (30 $\mathrm{mg}$ once a day). During tapering the steroid, previous lesion subsided (Fig. 1c), but newly developed lesion was found on the temporal area of the left eye at a dose of $10 \mathrm{mg} / \mathrm{d}$ of prednisolone (Fig. 1d). The relapse and remission was repeated for 6 months in spite of several courses of steroid treatment.

One week after the cessation of steroid, he complained of severe retro-orbital pain and blurred vision in his left eye. His left vision was decreased into count finger. The pupil was mid dilated and a relative afferent pupillary defect was found. Funduscopic examination

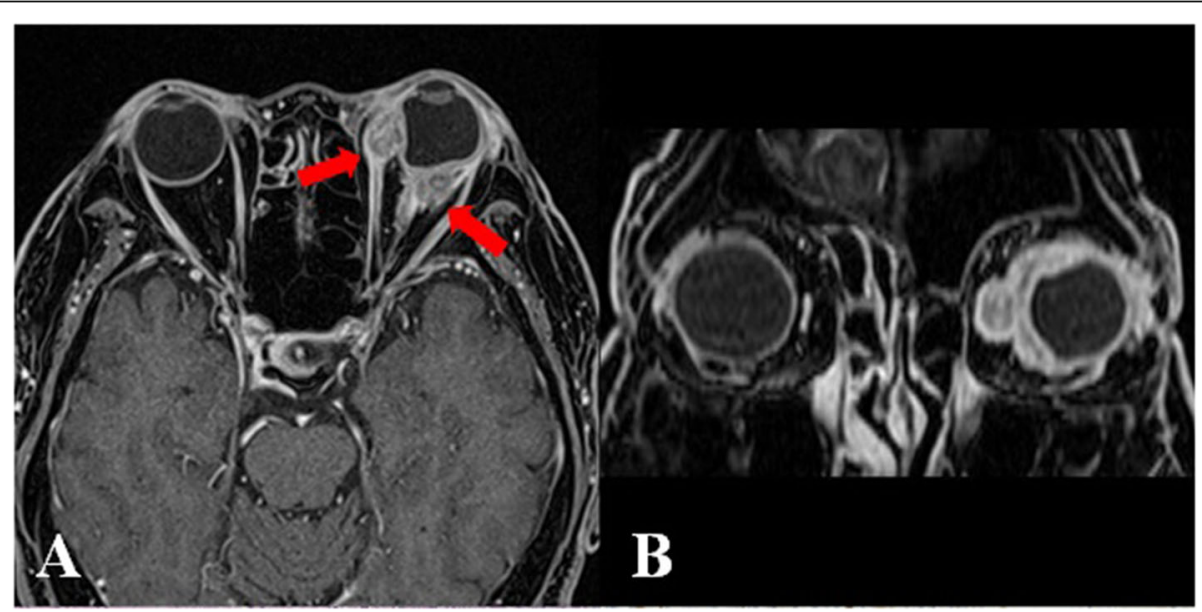

Fig. 2 Orbit MRI demonstrated enhancing soft tissue encasing the left globe $(\mathbf{a} \& \mathbf{b})$ with encasement of left medial rectus muscle and optic nerve (red arrows) 
demonstrated vitritis and disc swelling in the left eye. Orbit magnetic resonance imaging (MRI) demonstrated enhancing soft tissue encasing the left globe, where medial rectus muscle and optic nerve were enlarged and enhanced with scleral thickening (Fig. 2). On systemic evaluation, computed tomography (CT) scan of the chest revealed multiple clustered nodules in right lower lung (RLL) with tubular shadow and multiple small mediastinal lymph nodes. Video-assisted thoracoscopic surgery (VATS) biopsy was performed and immunohistochemical stain against IgG4 demonstrated that the number of IgG4-positive plasma cell were elevated to $>50$ cells per high-power field (Fig. 3b). In addition, an IgG4/IgG plasma cell ratio of $46.5 \%$ was observed (Fig. $3 \mathrm{c}$ and d). Serum IgG4 level was elevated at $210.7 \mathrm{mg} / \mathrm{dl}$.

The patient was diagnosed as IgG4-RD and began intravenous (IV) injection of hydrocortisone $50 \mathrm{mg}$ tid for 1 week, followed by IV methylprednisolone $60 \mathrm{mg}$ for 4 days. He was treated with $25 \mathrm{mg}$ of oral methylprednisolone daily for 2 weeks, the dose was gradually reduced by $5 \mathrm{mg}$ every 2 weeks and maintained methotrexate $10 \mathrm{mg}$ once a week. Long-term treatment with corticosteroids and a steroid-sparing agent (methotrexate) led to significant improvement in signs and symptoms. Visual acuity was improved into 20/40 and no recurrence was observed after 2 years of follow-up.

\section{Discussion and conclusions}

In 2011, comprehensive diagnostic criteria for IgG4-RD was defined as meeting two or more and including 1) of the following: 1) clinical examination shows characteristic diffuse/localized swelling or masses in single or multiple organs, 2) hematologic examination shows elevated serum IgG4 concentrations ( $\geq 135 \mathrm{mg} / \mathrm{dl}), 3$ ) histopathologic examination shows: marked lymphocyte and plasmacyte infiltration and fibrosis, infiltration of IgG4+ plasma cells: ratio of IgG4+ to IgG + cells $>40 \%$ and $>10$ IgG4+ plasma cells/HPF [8]. In this study, the patient had recurrent scleritis with soft tissue mass encasing the left globe and pulmonary nodules. Serum IgG4 level was $210.7 \mathrm{mg} / \mathrm{dl}$ and histologic examination of the lung nodule showed infiltration of IgG4+ plasma cells. Therefore, this patient fulfills three of diagnostic criterias and diagnosed as definite IgG4-RD.

IgG4-related ophthalmic disease (IgG4-ROD) forms a significant proportion of what has previously been labeled idiopathic orbital inflammation or reactive lymphoid hyperplasia. The lacrimal gland is most commonly involved but other orbital structures affected include the EOM, eyelid, the supraorbital and infraorbital nerves [79]. IgG4-ROD is a new and rare entity, which can be difficult to diagnose, especially in case of atypical features such as scleritis and conjunctival infiltration [10, 11]. There are a few reports of scleritis caused by IgG4-RD.

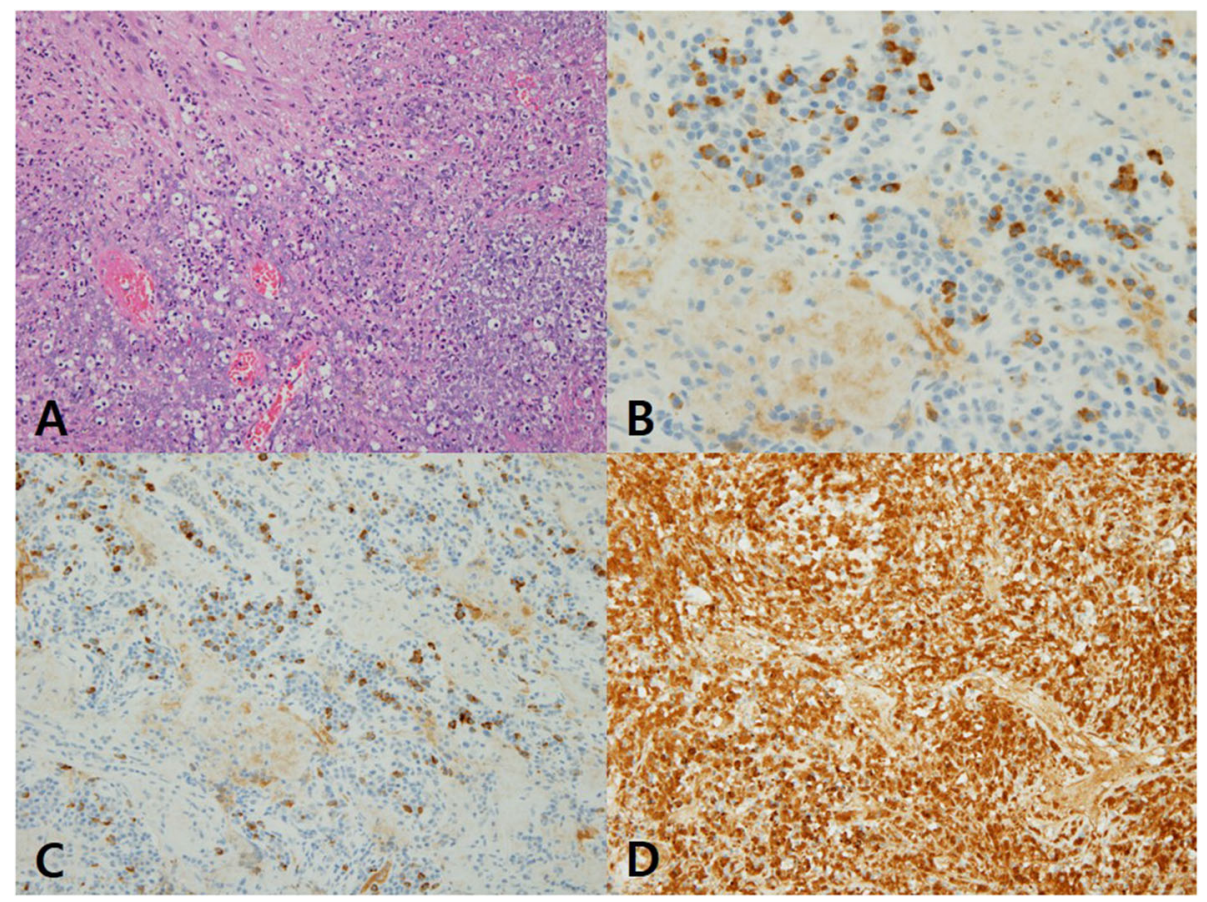

Fig. 3 Microscopic examination of the pulmonary nodule revealed necrotizing inflammation, dense fibrosis, marked lymphoplasmacytic infiltration, and increased lgG4+ plasma cells $(\mathbf{a}, \times 200$, Hematoxylin and eosin staining). Immunohistochemical staining showed an increased number of lgG4+ plasma cells (b, more than $50 \mathrm{lgG} 4$ cells per HPF, $\times 400$ ) and an elevated $\operatorname{lgG} 4+/ \mathrm{lgG}+$ ratio (c and $\mathbf{d}$, a ratio of lgG4+ to lgG+ cells of $46.5 \%)$ 
Moreover, two IgG4-RD cases involving the sclera were misdiagnosed as intraocular tumor [12, 13], and Ohno et al. [12] reported as choroidal tumor and enucleation of the eyeball was performed. Contrary to the previous studies, our patient could have had the opportunity to avoid the discouraging surgery by simply performing serological tests.

Long diagnostic delay in IgG4-RD, between 3.8 years and 7.5 years in other reports $[10,14]$, is responsible for permanent sequelae due to extensive fibrosis. In this case, although wax and wane of scleritis had been repeated for 6 months, IgG4-RD was confirmed through systemic work up and biopsy after the orbital mass encasing the optic nerve and medial retus muscle had developed. Inflammatory tissue biopsies and serum IgG4 levels are the only warrant of a timely and accurate diagnosis, and fluorodeoxyglucose-positron emission tomography (FDG-PET) scan is the most effective radiological test to investigate the presence of other organs involvement and to find the most accessible biopsy sites [15]. In our patient, pulmonary nodules in RLL was found at the chest CT scan and VATS biopsy revealed marked lymphoplasmacytic infiltration with IgG4+ plasma cells. We were unable to biopsy the orbital mass due to their proximity to the optic nerve. MRI finding did not show the specific feature of infraorbital nerve enlargement, differentiating optic nerve sheath inflammation of IgG4-ROD from other orbital disease [16]. However, histopathological findings of the pulmonary nodules, elevation of serum IgG4, and improvement of symptoms immediately after steroid administration are supportive of the diagnosis $[2,8,17]$.

Corticosteroids are typically the first line of therapy for IgG4-RD. Most patients respond well to oral glucocorticoid within several weeks, but the lesion sometimes recurs during steroid tapering or following the withdrawal. Immunosuppressive agents such as methotrexate, azathioprine, cyclophosphamide, 6-mercaptopurin and bortezomib have been used in IgG4-ROD for steroid-sparing effect. Since lymphoplasmocyic infiltration with CD20+ cells is one of the hallmarks of the disease, rituximab (an anti-CD20 monoclonal antibody) may be a treatment of choice, with a response rate of $90 \%$ in refractory cases $[18,19]$. Although treatment was started within 1 week of developing visual disturbance in this case, visual acuity was not recovered completely similar to other reports $[17,20]$ because of the involvement of optic nerve. The optic neuropathy leading to vision impairment may be due to a compressive or inflammatory process or both.

Many systemic diseases such as the autoimmune connective tissue diseases of rheumatoid arthritis, systemic lupus erythematosus, sero-negative spondylarthropathies and vasculitides such as granulomatosis with polyangiitis and polyarteritis nodosa had been reported to cause scleritis [21]. Recently, IgG4-RD has been introduced as an emerging cause of idiopathic scleritis.

Here, we presented a rare case of atypical presentation of IgG4-ROD with recurrent scleritis, optic neuropathy and EOM involvement. In cases of scleritis, the differential diagnosis should include IgG4-RD and serum IgG4 level is warranted as a part of the initial assessment of scleritis. Although this is the most common laboratory test performed for the diagnosis of IgG4-RD, serum IgG4 levels are normal in $30 \sim 40 \%$ patients, indicating a reduced sensitivity [22]. Therefore, if there are enlarged or inflamed tissues, proper pathological analysis should be performed to confirm the diagnosis of IgG4-RD.

IgG4-RD should be suspected in the face of any chronic inflammatory ophthalmological conditions and can be added as a novel cause of scleritis. It is important to promptly and accurately recognize IgG4-RD to allow commencement of appropriate treatment and to improve prognosis of patients. Early diagnosis and proper treatment can prevent irreversible organ damage and devastating visual morbidity.

\section{Acknowledgements}

This study was not presented at any other paper.

\section{Authors' contributions}

KSJ and LSU is responsible for acquisition of the clinical information and writing up of the manuscript. KSJ and KMS prepared the manuscript. AJH and $\mathrm{SJH}$ is responsible for reviewing the manuscript. PCY and LE crucially revised manuscript. All authors read and approved the final manuscript.

\section{Funding}

No funding was received for this research.

\section{Availability of data and materials \\ All data have been presented within the manuscript and in the form of images.}

\section{Ethics approval and consent to participate} Not applicable.

\section{Consent for publication}

Written informed consent was obtained from the patient for publication of this case report and any accompanying images. A copy of the written consent is available for review by the editor of this journal.

\section{Competing interests}

Choul Young Park is a section editor of BMC ophthalmology. The authors declare that they have no competing interests.

\section{Author details}

${ }^{1}$ Department of Ophthalmology, Pusan National University Yangsan Hospital, Pusan National University School of Medicine, 20 Geumo-ro, Mulgeum-eup, Yangsan-si, Gyeongsangnam-do 50612, South Korea. ${ }^{2}$ Research Institute for Convergence of Biomedical Science and Technology, Pusan National University Yangsan Hospital, Yangsan, South Korea. ${ }^{3}$ Department of Ophthalmology, School of Medicine, Kosin University, \#34 Amnam-dong, Seo-gu, Busan 602-702, South Korea. ${ }^{4}$ Department of Ophthalmology, Dongguk University Ilsan Hospital, \#27 Dongguk-ro, Ilsandong-gu, Goyang 10326, South Korea. ${ }^{5}$ Sensory Organ Research Center, Dongguk University, Goyang, South Korea. 
Received: 8 May 2020 Accepted: 16 December 2020

Published online: 05 January 2021

\section{References}

1. Sato Y, Ohshima K, Ichimura K, Sato M, Yamadori I, Tanaka T, et al. Ocular adnexal IgG4-related disease has uniform clinicopathology. Pathol Int. 2008; 58:465-70.

2. Umehara H, Okazaki K, Masaki Y, Kawano M, Yamamoto M, Saeki T, et al. A novel clinical entity, lgG4-related disease (IgG4RD): general concept and details. Mod Rheumatol. 2012;22:1-14.

3. McNab AA, McKelvie P. IgG4-related ophthalmic disease. Part I: background and pathology. Ophthalmic Plast Reconstr Surg. 2015;31:83-8.

4. Hamano H, Kawa S, Horiuchi A, Unno H, Furuya N, Akamatsu T, et al. High serum IgG4 concentrations in patients with sclerosing pancreatitis. N Engl J Med. 2001;344:732-8.

5. Geyer JT, Ferry JA, Harris NL, Stone JH, Zukerberg LR, Lauwers GY, et al. Chronic sclerosing sialadenitis (Küttner tumor) is an lgG4-associated disease. Am J Surg Pathol. 2010;34:202-10.

6. Stone JH, Zen Y, Deshpande V. IgG4-related disease. N Engl J Med. 2012;36: 539-51.

7. Go H, Kim JE, Kim YA, Chung HK, Khwarg SI, Kim CW, Jeon YK. Ocular adnexal IgG4-related disease: comparative analysis with mucosa-associated lymphoid tissue lymphoma and other chronic inflammatory conditions. Histopathology. 2012;60:296-312.

8. Pasquali T, Schoenfield L, Spalding SJ, Singh AD. Orbital inflammation in lgG4-related sclerosing disease. Orbit Amst Neth. 2011;30:258-60.

9. Derzko-Dzulynsky L. IgG4-related disease in the eye and ocular adnexa. Curr Opin Ophthalmol. 2017;28:617-22.

10. Philippakis E, Cassoux N, Charlotte F, LeHoang P, Bodaghi B, Bloch-Queyrat C, Touitou V. IgG4-related disease masquerading as recurrent Scleritis and chronic conjunctivitis. Ocul Immunol Inflamm. 2015;23:168-72.

11. Berkowitz E, Arnon E, Yaakobi A, Cohen Y, Tiosano B. IgG4-related disease presenting as isolated Scleritis. Case Rep Ophthalmol Med. 2017;2017: 4876587.

12. Ohno K, Sato Y, Ohshima K, Takata K, Ando M, Abd Al-Kader L, et al. IgG4related disease involving the sclera. Mod Rheumatol. 2014;24:195-8.

13. Ortiz AC, Gallo J, Paira S, Paira N. Immunoglobulin G4-related disease involving the sclera. J Clin Rheumatol. 2017;23:44-6.

14. Ebbo M, Daniel L, Pavic M, Sève P, Hamidou M, Andres E, et al. lgG4-related systemic disease: features and treatment response in a French cohort: results of a multicenter registry. Medicine (Baltimore). 2012;91:49-56.

15. Nguyen $V X$, De Petris $G$, Nguyen BD. Usefulness of PET/CT imaging in systemic lgG4-related sclerosing disease: a report of three cases. JOP J Pancreas. 2011;12:297-305.

16. Li J, Zhang Y, Zhou H, Wang L, Wang Z, Li H. Magnetic resonance imaging indicator of the causes of optic neuropathy in IgG4-related ophthalmic disease. BMC Med Imaging. 2019 Jun 18;19(1):49.

17. Takahashi Y, Kitamura A, Kakizaki H. Bilateral optic nerve involvement in immunoglobulin G4-related ophthalmic disease. J Neuroophthalmol. 2014; 34(1):16-9.

18. Khosroshahi A, Carruthers MN, Deshpande V, Unizony S, Bloch DB, Stone JH. Rituximab for the treatment of IgG4-related disease: lessons from 10 consecutive patients. Medicine (Baltimore). 2012;91:57-66.

19. Khosroshahi A, Stone JH. Treatment approaches to lgG4-related systemic disease. Curr Opin Rheumatol. 2011;23:67-71.

20. Hwang G, Jin SY, Kim HS. IgG4-related disease presenting as hypertrophic pachymeningitis and compressive optic neuropathy. Joint Bone Spine. 2016; 83:601-2.

21. Karim F, de Hoog J, Paridaens D, Verdijk R, Schreurs M, Rothova A, et al. IgG4-related disease as an emerging cause of scleritis. Acta Ophthalmol. 2017:95:e795-6.

22. Sah RP, Chari ST. Serologic issues in IgG4-related systemic disease and autoimmune pancreatitis. CurrOpin Rheumatol. 2011;23:108-13.

\section{Publisher's Note}

Springer Nature remains neutral with regard to jurisdictional claims in published maps and institutional affiliations.

\section{Ready to submit your research? Choose BMC and benefit from:}

- fast, convenient online submission

- thorough peer review by experienced researchers in your field

- rapid publication on acceptance

- support for research data, including large and complex data types

- gold Open Access which fosters wider collaboration and increased citations

- maximum visibility for your research: over $100 \mathrm{M}$ website views per year

At BMC, research is always in progress.

Learn more biomedcentral.com/submissions 